\title{
BMJ Open Association between frailty and disability among rural community- dwelling older adults in Sri Lanka: a cross-sectional study
}

\author{
Dhammika Deepani Siriwardhana (D) ,1,2 Manuj Chrishantha Weerasinghe, ${ }^{3}$ \\ Greta Rait, ${ }^{1}$ Shaun Scholes, ${ }^{4}$ Kate R Walters (i) ${ }^{1}$
}

To cite: Siriwardhana DD, Weerasinghe MC, Rait G, et al. Association between frailty and disability among rural community-dwelling older adults in Sri Lanka: a crosssectional study. BMJ Open 2020;10:e034189. doi:10.1136/ bmjopen-2019-034189

- Prepublication history and additional material for this paper are available online. To view these files, please visit the journal online (http://dx.doi org/10.1136/bmjopen-2019034189).

Received 09 September 2019 Revised 02 March 2020 Accepted 04 March 2020
Check for updates

(C) Author(s) (or their employer(s)) 2020. Re-use permitted under CC BY-NC. No commercial re-use. See rights and permissions. Published by BMJ.

For numbered affiliations see end of article.

\section{Correspondence to}

Dr Dhammika Deepani

Siriwardhana;

deepani.siriwardhana.15@ucl. ac.uk

\section{ABSTRACT}

Objective We examined the association between frailty and disability in rural community-dwelling older adults in Kegalle district of Sri Lanka.

Design A population-based cross-sectional study. Participants A total of 746 community-dwelling adults aged $\geq 60$ years.

Primary and secondary outcome measures Frailty was assessed using the Fried phenotype. Disability was operationalised in terms of having one or more activity limitation/s in instrumental activities of daily living (IADL) and basic activities of daily living (BADL).

Results The median age of the sample was (median 68; IQR $64-75$ ) years and $56.7 \%$ were female. $15.2 \%$ were frail and $48.5 \%$ were prefrail. The prevalence of $\geq 1 \mathrm{IADL}$ limitations was high, $84.4 \%$ among frail adults. $38.7 \%$ of frail adults reported $\geq 1$ BADL limitations. Over half of frail older adults $(58.3 \%)$ reported both $\geq 1$ physical and cognitive IADL limitations. Being frail decreased the odds of having no IADL limitations, and was associated with a higher count of IADL limitations. No significant association was found between prefrailty and number of IADL limitations.

Conclusions The prevalence of $\geq 1$ IADL limitations was high among rural community-dwelling frail older adults. Findings imply the greater support and care required for rural Sri Lankan frail older adults to live independently in the community.

\section{INTRODUCTION}

Disability has been defined as difficulties faced in any or all three areas of functioning: impairments (problems in body function and structure), activity limitations (difficulties an individual has in executing activities) and participation restrictions (problems an individual may experience in involvement of life situations). ${ }^{1}$ Conceptually, frailty is defined as a condition or syndrome resulting from decreased physiological reserve across multiple body systems as people age. ${ }^{23}$ As a consequence frail older adults are vulnerable to poor recovery after a minor stress event, such as non-injurious falls or infection. ${ }^{3}$

\section{Strengths and limitations of this study}

- To the best of the authors' knowledge this is the first study conducted in the World Health Organization (WHO) South-East Asia region to assess the association between frailty and disability among community-dwelling older adults.

- Study included a large representative sample of rural community-dwelling older adults with a very high response rate $(99.5 \%)$.

- Disability (limitations in instrumental activities of daily living (IADL) and basic activities of daily living (BADL)) has been assessed using validated instruments for Sri Lanka.

- We assessed the self-reported capacity of participants to perform IADL tasks rather than selfreported actual performance. Therefore, there is a possibility of both under and/or over estimation of the actual performance of participants.

- The cross-sectional nature of the study design does not allow us to establish temporal relationships or causality.

Frailty has been operationalised as a distinct concept from disability although they often overlap with each other. ${ }^{4}$ Frailty is commonly defined using a syndromic approach that includes measurements of five physical features: shrinking (unintentional weight loss), poor endurance and energy (self-reported exhaustion), weakness, slowness and low physical activity level. ${ }^{2}$ Many people with frailty also have disability. ${ }^{5}$ Likewise there are many people with long-term disability who are not frail. ${ }^{5}$ Frailty may be a cause of incident and worsening disability in community-dwelling older adults. ${ }^{2}{ }^{6} \mathrm{We}$ found few studies estimating the prevalence of disability in depth, for example, prevalence of specific limitations in instrumental activities of daily living (IADL) and basic activities of daily living (BADL) across frailty status 
among community-dwelling older adults. These studies were from Canada, England and Egypt. ${ }^{7-9}$

Sri Lanka is one of the fastest growing ageing countries in the WHO South-East Asia region ${ }^{10}$ (here onwards referred to as South-East Asia region). To the best of our knowledge, there are no studies estimating the prevalence of frailty and disability simultaneously and investigating the association between frailty and disability in Sri Lanka or in any other country in South-East Asia. The development of disability is a complex process that involves biological and disease conditions that are integrated into the social and environmental context. ${ }^{11}$ Therefore, the strength of the association between frailty and disability could be influenced by context specific factors such as education level, socioeconomic status, ethnicity, life style factors and the cultural context that shapes them. Given this heterogeneity, we cannot extrapolate the findings from one region to other settings. Therefore, understanding the disabilities in different older populations in the South-East Asian region is important. It will reflect the activities where older adults are mostly dependent and help to understand to some extent the caregiver burden in older populations. We conducted this study to estimate the prevalence of disability across frailty status and investigate the cross-sectional association between frailty and disability in rural community-dwelling older adults in Kegalle district of Sri Lanka.

\section{METHODS}

\section{Study design, setting and participants}

This is a population-based cross-sectional study conducted with older adults aged $\geq 60$ years permanently living in the rural sector of Kegalle district of Sri Lanka. The estimated sample size required for this study was 750 participants. A three-stage probability sampling design was used; details of the sample size calculation, sampling technique and recruitment of participants have been reported elsewhere. $^{12}$

\section{Measurements}

Assessment of frailty

Frailty was assessed using the Fried phenotype ${ }^{2}$ comprising five components; shrinking, self-reported exhaustion, weakness, slowness and low physical activity level. Shrinking was operationalised as a body mass index $(\mathrm{BMI})<18.5 \mathrm{~kg} / \mathrm{m}^{2}$. Poor endurance and energy as indicated by self-reported exhaustion was assessed using two questions: 'I felt that everything I did was an effort' and 'I could not get going' from the Center for Epidemiologic Studies-Depression Scale. ${ }^{13} 14$ If the answer was three or more days in the last week to either of these two questions, the respondent was considered as frail for this component. Being in the lowest quintile of grip strength after adjusting for sex and BMI quartiles of the study population was considered as indicative of weakness. Participants' walking time in the highest time quintile after adjusting for sex and median standing height of the study population was considered as indicative of slowness. Individuals unable to perform the walking test were also considered as frail for this component. Low physical activity level was measured using the International Physical Activity Questionnaire Short Form. ${ }^{15} 16$ Participants in the lowest quintile of weekly kilocalorie expenditure adjusted for sex were considered as frail for this component. As proposed in the original study, ${ }^{2}$ participants with three or more components were considered as frail, those with one or two components were considered as prefrail and those with none of the five components described above were considered as robust/non-frail.

\section{Assessment of disability}

Disability was operationalised in terms of having one or more activity limitation/s in IADL and BADL, measured using the original Lawton scale and Barthel index, respectively that have been validated in the Sri Lankan context. ${ }^{17} 18$ IADL tasks assess an individual's ability to live independently in the community. The original Lawton IADL scale assessed eight activities including shopping, housekeeping, handling finances and so on. Self-reported capacity of performing each activity was recorded. Using the scale's scoring protocol, participants were classified into two categories as 'independent' and 'dependent' for each item. ${ }^{19}$ Following $\mathrm{Ng}$ et al we further classified these IADL activities into two domains; physical and cognitive. ${ }^{20}$

BADL tasks involve self-care activities that require fundamental skills to manage basic physical needs. The Barthel index consists of 10 items and measures BADL and mobility, ${ }^{21}$ including feeding, bathing, dressing, continence and mobility and so on. Self-reported actual performance was recorded. According to the response for each item, participants were classified into two groups as 'independent' and 'dependent' (online supplementary file).

\section{Covariates}

Sociodemographic covariates of participants included sex, age, ethnicity, marital status, living arrangement, education level, longest-held occupation according to the Sri Lanka Standard Classification of Occupation, ${ }^{22}$ and subjective financial strain. ${ }^{23}$ Health-related variables included multimorbidity defined as coexistence of two or more concurrent chronic medical conditions, ${ }^{24}$ cognitive status assessed using the Montreal Cognitive Assessment (MoCA) ${ }^{25}$ self-perceived vision ability, self-perceived hearing ability and social support assessed using the Oslo-3 social support scale. The Oslo-3 social support scale score ranged from 3 to 14, a higher score indicates higher social support. ${ }^{26}$ The MoCA score ranged from 0 to 31 , a higher score indicates higher cognitive status. ${ }^{25}$ The maximum score of MoCA has increased up to 31 in our study with the addition of one point for low education (if $\leq 12$ years of education). 


\section{Statistical analyses}

All statistical analyses were performed in Stata V.15 accounting for the complex survey design ${ }^{27}$ unless otherwise stated. Missing data were minimal (3.6\%) therefore, descriptive analysis was performed with available cases and the regression model was performed on complete cases.

\section{Descriptive statistics}

Sociodemographic, health characteristics and frailty status of the overall sample and across the disability status were calculated using percentages. A Venn diagram was used to illustrate the overlap between frailty, physical IADL limitations and cognitive IADL limitations.

\section{Association between frailty and IADL limitations}

The total number of IADL limitations is a count dependent variable ranging from 0 to 8 . There was an excess number of zeros (overall $67.2 \%$ participants had no IADL limitations). Therefore, we used zero-inflated Poisson (ZIP) regression models to estimate the associations between frailty status and the number of IADL limitations. ZIP regression models for a count dependent variable with excess zeros assume two latent groups: the first is the group of 'sure zeros'/'not-at-risk' latent class (the group expected to have a count of zero) and the second is the group of 'non-sure zeros' (or the 'at-risk' latent class). ${ }^{28}$ ZIP models comprise two parts. First, a logistic regression model is used for predicting the probability of participants belonging to the latent class of 'sure zeros'. Second, a Poisson regression model is used for predicting the count of the dependent variable for those participants predicted to belong to the latent 'non-sure zero' / 'at-risk' group. As in other studies, to interpret the parameter estimates for the frailty groups, we interpret the parameters of the logistic regression model using ORs, and interpret the parameters of the Poisson regression model (count component among the non-sure zeros) using the rate ratios (RRs). Unadjusted, age-adjusted and sex-adjusted and multivariable-adjusted ZIP models were fitted to estimate the associations between prefrailty, frailty and number of IADL limitations. Multivariable models were built by a stepwise addition of covariates to the ageadjusted and sex-adjusted models. Variables included in the multivariable model were based on the literature and clinical relevance.

\section{Association between frailty and BADL limitations}

Modelling the association between frailty status and BADL limitations was not performed due to the lack of heterogeneity in the presence of $\geq 1$ BADL limitations across the frailty groups.

\section{Data collection}

Five trained nursing graduates collected data from the entire sample, supervised by the lead author (DDS). No incentives were provided for the participants.
Patient and public involvement

No patient involved.

This manuscript was written according to the Strengthening the Reporting of Observational Studies in Epidemiology statement. ${ }^{29}$

\section{RESULTS}

\section{Data screening and missing values}

Thirteen participants reported they had never used a telephone and nine participants reported they had never cooked. One participant reported never having done both. Therefore, there was missing data for 23 participants for $\geq 1$ IADL items. These were subsequently excluded from the main analysis. The social support score was missing for four participants, resulting in the exclusion of a total of $27(3.6 \%)$ participants from final regression analysis. There was no missing data for the BADL items.

\section{Sociodemographic and health characteristics of the overall sample}

The age range of the participants was $60-94$ years. The median age of the sample was (median 68; IQR 64-75) years. The sample was $56.7 \%$ female and the majority were Sinhalese ethnicity (table 1). The MoCA score ranged from 3 to 31 with a median 20; IQR 15-23.

\section{Prevalence of frailty status}

According to the Fried phenotype of frailty, 15.2\% (95\% CI $12.4 \%$ to $18.7 \%$ ) were frail, $48.5 \%$ (95\% CI $43.9 \%$ to $53.2 \%$ ) were prefrail and $36.2 \%$ (95\% CI $32.4 \%$ to $40.3 \%$ ) were robust. ${ }^{12}$

\section{Prevalence of disability across sociodemographic characteristics and health-related factors}

The prevalence of $\geq 1$ IADL and $\geq 1$ BADL limitations was slightly higher among males compared with females. The prevalence of $\geq 1$ IADL and $\geq 1$ BADL limitations was also higher across advancing age, older adults with lower education level, lower long-held occupation skill category and with low social support. As expected, older adults with multimorbidity, 'poor/fair' self-perceived vision and 'poor/fair' hearing ability reported higher prevalence of $\geq 1$ IADL and $\geq 1$ BADL limitations compared with their counterparts without these conditions (table 2). The median MoCA score of older adults with $\geq 1$ IADL limitations was lower (median 16; IQR 11.5-21) compared with adults with no IADL limitations (median 21; IQR 18-23).

\section{Prevalence of disability and specific IADL and BADL limitations by frailty status}

The prevalence of $\geq 1$ IADL and $\geq 1$ BADL limitations (disability) in the total sample was $32.8 \%$ (95\% CI $28.7 \%$ to $37.2 \%$ ) and $7.2 \%$ (95\% CI $5.0 \%$ to $10.4 \%$ ), respectively. Of the frail participants, $84.4 \%$ (95\% CI $68.9 \%$ to $93.0 \%$ ) and $38.7 \%$ (95\% CI $26.1 \%$ to $53.1 \%$ ) reported $\geq 1$ IADL and $\geq 1$ BADL limitations, respectively. Approximately two-thirds of frail older adults had limitations in physical IADLs like shopping and food preparation 
Table 1 Sociodemographic and health characteristics of the overall sample

\begin{tabular}{lll}
\hline Covariate & $\begin{array}{l}\text { Unweighted } \\
\text { sample } \\
\%^{*} \text {, (n) }\end{array}$ & $\begin{array}{l}\text { Weighted } \\
\text { sample, \%* }\end{array}$ \\
\hline Sex & & \\
Male & $46.8(349)$ & 43.3 \\
\hline Female & $53.2(396)$ & 56.7 \\
\hline Age group (years) & & \\
\hline $60-64$ & $33.3(248)$ & 35.7 \\
$65-69$ & $26.7(199)$ & 25.3 \\
\hline $70-74$ & $13.3(99)$ & 17.0 \\
$75-79$ & $13.4(100)$ & 11.2 \\
$\geq 80$ & $13.3(99)$ & 10.8 \\
\hline
\end{tabular}

\section{Ethnicity}

$\begin{array}{lcr}\text { Sinhalese } & 96.9(722) & 97.4 \\ \text { Other } & 3.1(23) & 2.6 \\ \begin{array}{l}\text { Marital status } \\ \text { Married/cohabiting }\end{array} & 61.3(457) & 59.6 \\ \begin{array}{l}\text { Never-married/widowed/ } \\ \text { separated/divorced }\end{array} & 38.7(288) & 40.4 \\ \text { Living arrangement } & & \\ \text { Children/other family } & 82.7(616) & 83.0 \\ \text { With spouse only } & 11.3(84) & 10.7 \\ \text { Alone } & 6.0(45) & 6.3\end{array}$

Social support

\begin{tabular}{lcc}
\hline Poor (score 3-8) & $4.3(32)$ & 4.3 \\
\hline Moderate (score 9-11) & $16.6(124)$ & 16.7 \\
\hline Strong (score 12-14) & $78.5(585)$ & 79.0 \\
\hline Missing & $0.6(4)$ & - \\
\hline Education level & & \\
\hline No formal education/ primary & $28.7(214)$ & 28.7 \\
\hline Lower secondary & $35.2(262)$ & 35.3 \\
\hline Upper secondary or above & $36.1(269)$ & 36.0 \\
\hline Longest-held occupation & & \\
\hline Never-employed/skill level 1 & $42.4(316)$ & 43.8 \\
\hline Skill level 2 & $39.3(293)$ & 38.5 \\
\hline Skill level 3 or 4 & $18.3(136)$ & 17.7 \\
\hline Perceived financial strain & & \\
\hline Finding it difficult/very difficult & $20.4(152)$ & 20.4 \\
\hline Just about getting by & $54.5(406)$ & 55.0 \\
\hline Living comfortably & $25.1(187)$ & 24.6 \\
\hline Multimorbidity & & \\
\hline Yes & $40.9(305)$ & 41.4 \\
\hline No & $59.1(440)$ & 58.6 \\
\hline Self-perceived vision & & 50.0 \\
\hline Poor/fair & $50.9(379)$ & \\
\hline Good/very good/excellent & $49.1(366)$ & \\
\hline Self-perceived hearing & & \\
\hline & & \\
\hline
\end{tabular}

Continued
Table 1 Continued

\begin{tabular}{lll}
\hline & $\begin{array}{l}\text { Unweighted } \\
\text { sample } \\
\%^{*} \text {, (n) }\end{array}$ & $\begin{array}{l}\text { Weighted } \\
\text { sample, \%* }\end{array}$ \\
\hline Poor/fair & $34.0(253)$ & 32.8 \\
\hline Good/very good/excellent & $66.0(492)$ & 67.2 \\
\hline
\end{tabular}

${ }^{*}$ Column percentage.

whereas nearly half of frail participants had limitations in managing their own medication. Limitations in physical IADLs were more prevalent compared with cognitive IADL limitations among frail older adults (table 3).

Overlap of frailty, physical IADL limitations and cognitive IADL limitations

Based on unweighted data, 36.6\% (264/722) of all participants were either frail or had physical or cognitive IADLs. Figure 1 shows the overlaps between frailty, physical IADL limitations and cognitive IADL limitations in the unweighted sample. In the overall sample, only a small group, 9.3\% (67/722) were frail and had both $\geq 1$ physical and cognitive IADL limitations. 20.6\% (149/722) of the overall sample reported to have either $\geq 1$ physical or cognitive IADL limitations without frailty. However, among the frail participants (shown by the long-dash dot pattern in figure 1), $58.3 \%(67 / 115)$ reported both $\geq 1$ physical and cognitive IADL limitations.

\section{Association between frailty and IADL limitations}

The association between frailty and the number of IADL limitations in unadjusted, age-adjusted and sex-adjusted and multivariable-adjusted ZIP regression models adjusted for different covariates at each stage is presented in table 4. In the logistic regression part of the model, being frail as opposed to being robust significantly decreased the odds of having no IADL limitations. In the Poisson part of the model, being frail as opposed to being robust increased the estimated number of IADL limitations fourfold. However, the strength of the association was gradually attenuated with the addition of covariates. We did not find any significant association with prefrailty (vs robust) and IADL limitations (table 4).

Table 5 presents complete results of the final multivariable ZIP model (model 7 in table 4). The estimated odds of reporting no IADL limitations (ie, being in the 'sure zero'/'not-at-risk group') were approximately 90.0\% lower for frail participants compared with their robust counterparts. Among those estimated to be 'at-risk', the estimated number of IADL limitations was four times higher for frail as opposed to robust participants (RR: 4.16 ; $95 \%$ CI 2.27 to 7.60$)$.

\section{DISCUSSION}

\section{Summary of main findings}

The prevalence of $\geq 1$ IADL limitations was high ( $84.4 \%$ ) among rural community-dwelling frail older adults in Sri 
Table 2 Prevalence of disability across sociodemographic
characteristics and health-related factors

\begin{tabular}{|c|c|c|}
\hline \multirow[b]{2}{*}{ Covariate } & \multicolumn{2}{|c|}{$\begin{array}{l}\text { Prevalence of the limitations } \\
(95 \% \mathrm{Cl}), \%\end{array}$} \\
\hline & $\geq 1$ IADL & $\geq 1$ BADL \\
\hline \multicolumn{3}{|l|}{ Sex } \\
\hline Male & 35.2 (30.1 to 40.6$)$ & 9.0 (5.9 to 13.6$)$ \\
\hline Female & 31.0 (26.0 to 36.5$)$ & 5.8 (3.6 to 9.3 ) \\
\hline \multicolumn{3}{|l|}{ Age group (years) } \\
\hline $60-64$ & 13.6 (8.9 to 20.1$)$ & $1.2(0.2$ to 5.6$)$ \\
\hline $65-69$ & 21.2 (13.2 to 32.0$)$ & 3.4 (1.4 to 8.0 ) \\
\hline $70-74$ & 40.2 (28.4 to 53.2 ) & 5.2 (1.9 to 13.3$)$ \\
\hline $75-79$ & 57.8 (43.8 to 70.6$)$ & 15.7 (7.8 to 29.0$)$ \\
\hline$\geq 80$ & 85.9 (74.4 to 92.7$)$ & 30.1 (20.0 to 42.6 ) \\
\hline \multicolumn{3}{|l|}{ Ethnicity } \\
\hline Sinhalese & 33.0 (28.6 to 37.6$)$ & 7.2 (4.9 to 10.5$)$ \\
\hline Other & 27.5 (17.4 to 40.5$)$ & 6.1 (1.0 to 30.0 ) \\
\hline \multicolumn{3}{|l|}{ Marital status } \\
\hline Married/cohabiting & 27.4 (20.9 to 35.2$)$ & 6.3 (3.7 to 10.5$)$ \\
\hline $\begin{array}{l}\text { Never-married/ } \\
\text { widowed/separated/ } \\
\text { divorced }\end{array}$ & 40.7 (34.0 to 47.8$)$ & 8.5 (5.5 to 13.1$)$ \\
\hline
\end{tabular}

Living arrangement

\begin{tabular}{|c|c|c|}
\hline Children/other family & 33.3 (28.9 to 38.0 ) & 7.3 (5.1 to 10.4$)$ \\
\hline With spouse only & 32.4 (20.3 to 47.6$)$ & 7.9 (3.1 to 18.8$)$ \\
\hline Alone & 27.2 (12.9 to 48.4$)$ & 4.5 (0.6 to 27.5$)$ \\
\hline \multicolumn{3}{|l|}{ Social support } \\
\hline Poor (score 3-8) & 62.6 (35.1 to 83.8 ) & 16.0 (5.4 to 39.1$)$ \\
\hline Moderate (score 9-11) & 35.3 (24.3 to 48.0 ) & 10.3 (5.6 to 18.0$)$ \\
\hline Strong (score 12-14) & 31.1 (26.3 to 36.4$)$ & 6.1 (3.7 to 9.7 ) \\
\hline Missing & - & - \\
\hline \multicolumn{3}{|l|}{ Education level } \\
\hline $\begin{array}{l}\text { No formal education/ } \\
\text { primary }\end{array}$ & 49.6 (39.3 to 59.9) & 11.3 (6.9 to 18.0$)$ \\
\hline Lower secondary & $32.9(26.4$ to 40.1$)$ & 6.8 (3.4 to 12.9$)$ \\
\hline $\begin{array}{l}\text { Upper secondary or } \\
\text { above }\end{array}$ & 19.5 (15.5 to 24.3 ) & 4.4 (2.4 to 7.8$)$ \\
\hline
\end{tabular}

\begin{tabular}{|c|c|c|}
\hline \multicolumn{3}{|l|}{ Longest-held occupation } \\
\hline $\begin{array}{l}\text { Never-employed/skill } \\
\text { level } 1\end{array}$ & 40.7 (33.7 to 48.2$)$ & 8.3 (5.3 to 12.8$)$ \\
\hline Skill level 2 & 28.0 (21.9 to 35.1$)$ & 6.8 (3.7 to 12.0$)$ \\
\hline Skill level 3 or 4 & $23.9(17.2$ to 32.1$)$ & 5.4 (2.6 to 11.0$)$ \\
\hline \multicolumn{3}{|l|}{ Perceived financial strain } \\
\hline $\begin{array}{l}\text { Finding it difficult/very } \\
\text { difficult }\end{array}$ & 45.2 (35.1 to 55.7$)$ & 9.5 (5.4 to 16.3$)$ \\
\hline Just about getting by & 29.8 (24.8 to 35.2$)$ & 7.7 (4.9 to 11.8$)$ \\
\hline Living comfortably & 29.9 (22.7 to 38.2$)$ & 4.2 (1.4 to 12.2$)$ \\
\hline \multicolumn{3}{|l|}{ Multimorbidity } \\
\hline Yes & 37.0 (27.9 to 47.2$)$ & $9.3(5.6$ to 15.1$)$ \\
\hline No & 29.8 (24.7 to 35.6$)$ & 5.7 (3.6 to 9.0$)$ \\
\hline
\end{tabular}

Continued
Table 2 Continued

\begin{tabular}{llc}
\hline & \multicolumn{2}{l}{$\begin{array}{l}\text { Prevalence of the limitations } \\
\text { (95\% Cl), \% }\end{array}$} \\
\cline { 2 - 3 } Covariate & $\geq \mathbf{1}$ IADL & $\geq 1$ BADL \\
\hline $\begin{array}{l}\text { Self-perceived vision } \\
\text { Poor/fair }\end{array}$ & $42.4(36.9$ to 48.0$)$ & $10.2(6.8$ to 15.0$)$ \\
$\begin{array}{l}\text { Good/very good/ } \\
\text { excellent }\end{array}$ & $23.4(18.3$ to 29.4$)$ & $4.2(2.3$ to 7.6$)$ \\
$\begin{array}{l}\text { Self-perceived hearing } \\
\text { Poor/fair }\end{array}$ & $45.4(37.2$ to 53.8$)$ & $10.0(6.5$ to 15.0$)$ \\
\hline $\begin{array}{l}\text { Good/very good/ } \\
\text { excellent }\end{array}$ & $26.7(21.4$ to 32.7$)$ & $5.9(3.6$ to 9.5$)$ \\
\hline
\end{tabular}

BADL, basic activities of daily living; IADL, instrumental activities of daily living.

Lanka. Over half of frail older adults (58.3\%) reported both $\geq 1$ physical and cognitive IADL limitations. Physical IADL limitations were more prevalent compared with cognitive IADL limitations. $38.7 \%$ frail older adults in our study reported $\geq 1$ BADL limitations. Being frail as opposed to being robust decreased the odds of reporting no IADL limitations. Among those estimated to be at risk of having $\geq 1$ IADL limitations, the estimated number of IADL limitations was four times higher for frail compared with robust participants after adjustment for covariates. However, we found no significant association between prefrailty and IADL limitations.

\section{Comparison with the existing literature}

The prevalence of $\geq 1$ IADL limitations appears to be higher among frail Sri Lankan older adults (84.4\%) compared with frail older adults in USA $(60.0 \%),{ }^{2}$ England $(64.5 \%)^{7}$ and Egypt $(72.1 \%){ }^{8}$ In contrast, the prevalence of $\geq 1 \mathrm{BADL}$ limitations were higher among frail older adults in England $(57.1 \%)^{7}$ and in Egypt $(44.2 \%)^{8}$ than in our Sri Lankan population $(38.7 \%)$. The prevalence of $\geq 1$ BADL limitations among frail older adults in the USA study was lower (27.4\%) compared with ours. Minimum age of the participants included in the Egyptian and English studies was $\geq 60$ years whereas it was $\geq 65$ years in the USA study. However, these findings need to be compared and interpreted with caution considering the study context (country) specific differences (eg, complexities associated with performing certain tasks, eg, meal preparation, shopping; sex-specific differences in performing some tasks; and cultural expectations for example, in some cultures older adults are not expected to take on household duties) and methodological heterogeneity. In addition to the cultural or context specific variations, these differences in the prevalence of IADL and BADL limitations by frailty status could be partly explained by the heterogeneity of study methodology, including differences in study population and in disability assessment methods. There can be differences in the way each study framed the question, the way participants 
Table 3 Prevalence of disability and specific IADL and BADL limitations by frailty status

\begin{tabular}{|c|c|c|c|c|}
\hline \multirow[b]{2}{*}{ Disability } & \multicolumn{4}{|c|}{ Prevalence across total sample and by frailty status $(95 \% \mathrm{Cl}), \%$} \\
\hline & All & Robust & Prefrail & Frail \\
\hline \multicolumn{5}{|l|}{ Self-reported disability } \\
\hline$\geq 1$ physical IADL limitations & $27.0(23.7$ to 30.6$)$ & 11.1 (7.1 to 17.2$)$ & $22.3(17.9$ to 27.4$)$ & 79.8 (66.9 to 88.6$)$ \\
\hline$\geq 1$ cognitive IADL limitations & $18.6(15.1$ to 22.7$)$ & 4.7 (2.5 to 8.7$)$ & 15.1 (10.8 to 20.8$)$ & $62.5(44.2$ to 77.9$)$ \\
\hline \multicolumn{5}{|l|}{ Physical IADL } \\
\hline Shopping & 19.6 (16.6 to 23.1$)$ & $4.1(1.6$ to 9.7$)$ & 16.1 (12.4 to 20.7$)$ & $67.9(55.6$ to 78.1$)$ \\
\hline Food preparation & $18.1(14.9$ to 22.0$)$ & $8.2(4.9$ to 13.4$)$ & $11.9(8.8$ to 15.9$)$ & $61.7(49.7$ to 72.4$)$ \\
\hline Mode of transportation & $7.3(5.1$ to 10.5$)$ & 0.0 & $3.2(1.2$ to 8.3$)$ & 37.8 (26.3 to 50.8$)$ \\
\hline \multicolumn{5}{|l|}{ Cognitive IADL } \\
\hline Responsibility of own medication & 11.7 (9.1 to 15.0$)$ & $1.7(0.5$ to 5.2$)$ & 8.3 (5.5 to 12.2$)$ & 46.6 (32.8 to 60.9$)$ \\
\hline Ability to use telephone & 9.5 (7.1 to 12.5$)$ & $3.2(1.4$ to 7.6$)$ & 7.6 (4.5 to 12.5$)$ & 30.5 (18.7 to 45.5$)$ \\
\hline Ability to handle finances & 7.4 (5.1 to 10.6$)$ & $0.5(0.0$ to 5.5$)$ & 3.7 (1.6 to 7.9$)$ & 35.7 (22.4 to 51.6$)$ \\
\hline \multicolumn{5}{|l|}{ Specific limitations in $B A D L$} \\
\hline Feeding & $4.2(2.5$ to 6.9$)$ & 0.0 & 0.7 (0.1 to 3.4$)$ & 25.1 (15.1 to 38.8$)$ \\
\hline Bathing & 3.7 (2.4 to 5.7$)$ & 0.0 & 0.7 (0.1 to 4.7$)$ & $22.0(14.7$ to 31.6$)$ \\
\hline Dressing & 3.5 (1.6 to 7.7$)$ & 0.0 & $0.3(0.0$ to 3.9$)$ & 22.1 (9.8 to 42.4 ) \\
\hline Toilet use & 3.1 (1.6 to 5.7$)$ & 0.0 & $0.2(0.0$ to 2.4$)$ & 19.4 (10.2 to 33.8$)$ \\
\hline Grooming & 2.4 (1.2 to 4.8$)$ & 0.0 & 0.5 (0.1 to 2.0$)$ & 14.4 (7.3 to 26.4$)$ \\
\hline
\end{tabular}

BADL, basic activities of daily living; IADL, instrumental activities of daily living.

interpreted these items and the response options available, and the respondent (whether the respondent was an older adult or a caregiver).

There is a potential bidirectional relationship between frailty and cognitive impairment. ${ }^{30}$ It has been also found that IADL limitations are consistently present with those who have mild cognitive impairment. ${ }^{31}$ In our sample physical IADL limitations appeared to be more common among frail participants compared with cognitive IADL limitations. However, this finding was in line with our expectations given that the Fried phenotype captures physical frailty. Alternatively, in the Sri Lankan context, certain physical IADL tasks (eg, food preparation and shopping) could be more demanding for frail older adults compared with cognitive IADL tasks. In our study the vast majority $(96.0 \%)$ of older adults lived with their spouse or children and therefore family support for older adults is very high.

None of the robust older adults and a very few number of prefrail older adults had BADL disability. Majority
(60.0\%) of the participants in our study belonged to young-old (60-69 years) age category. The age range and median age of the participants in our sample were 60-94 years and median 68; IQR 64-75 years, respectively. This might be the main reason for observed less BADL disability in our study as BADL disabilities are strongly associated with higher age. We observed a similar pattern in a study conducted in Canada $(n=740)$ even with a much older sample compared with ours (age range: 75-96 years; mean (SD) 79.6 (4.0) years). In this study, BADL disability was defined as needing help or having difficulty with one or more following items: eating, dressing, transferring, bathing and toileting. The percentage of participants with $\geq 1$ BADL limitations in non-frail, prefrail and frail was $0.6 \%, 4.9 \%$ and $29.1 \%$, respectively. ${ }^{9}$

\section{Strengths and limitations}

To the best of the authors' knowledge this is the first study of its kind conducted in the WHO South-East Asia 


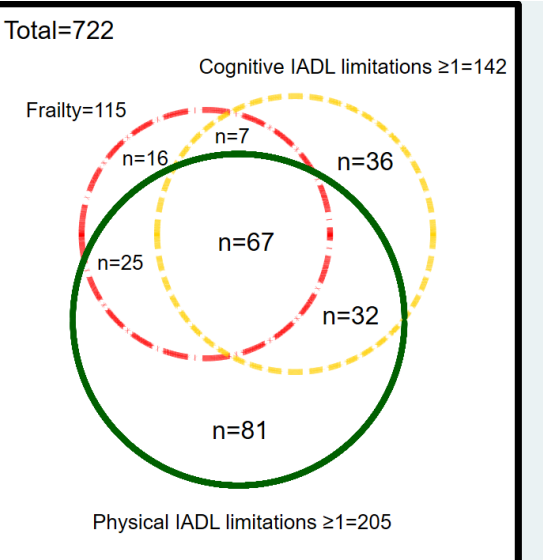

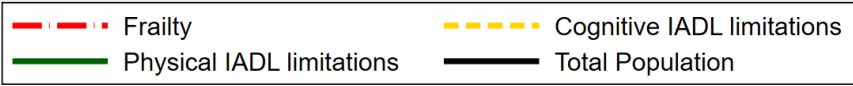

Figure 1 Overlap of frailty, physical IADL limitations and cognitive IADL limitations. Physical IADL activities: shopping, food preparation, mode of transportation, housekeeping, laundry. Cognitive IADL activities: responsibility of own medication, ability to use telephone, ability to handle finances. 63.4\% (458/722) participants have neither frailty nor cognitive IADL nor physical IADL limitations. 2.2\% (16/722) participants have only frailty. 11.2\% (81/722) participants have only physical IADL limitations. 5.0\% (36/722) participants have only cognitive IADL limitations. $3.5 \%(25 / 722)$ participants have frailty and physical IADL limitations. 1.0\% (7/722) participants have frailty and cognitive IADL limitations. 4.4\% (32/722) participants have physical IADL and cognitive IADL limitations. 9.3\% (67/722) participants have frailty and both physical IADL and cognitive IADL limitations. IADL, instrumental activities of daily living.

region. We conducted this study with a large representative sample of community-dwelling older adults and the response rate was very high. The frailty assessment method used (Fried phenotype) has been extensively used and has good predictive validity. ${ }^{2}$ Instruments used to assess disability have been validated in Sri Lanka. ${ }^{17} 18$ We were cautious not to over adjust the model when estimating the relationship between frailty and disability by including cognitive assessment as it could potentially lie on the causal pathway and presumed to have a bidirectional relationships with frailty. ${ }^{32}$ We assessed the selfreported capacity of participants to perform IADL tasks rather than self-reported actual performance. Therefore, there is a possibility of both under and/or over estimation of the actual performance of participants. We excluded participants who could not give informed consent (eg, advanced stages of dementia) and excluded those who were terminally ill. These exclusions may have led to an underestimation of both true prevalence of frailty and disability. Although we only recruited participants capable of giving informed consent to participate in our study, there seemed to be a small number participants with severe cognitive impairment (according to proposed MoCA score ranges-however, research for these severity ranges has not been established yet ${ }^{33}$ ). This might have an impact on the reliability of the self-reported IADL and BADL limitations provided by these participants. Finally, the cross-sectional nature of the study design does not allow us to establish temporal relationships or causality.

\section{Implications for health, social services and future research} The increasing size of a frail older population is one of the biggest challenges to health and welfare services. ${ }^{34}$ Frail older adults are vulnerable to developing disability which leads to higher care needs and resource use. ${ }^{35}$ In Sri Lanka, spouses and/or children are the main caregivers of community-dwelling older adults. The higher prevalence of IADL limitations among frail older adults

Table 4 Association between prefrailty, frailty and instrumental activities of daily living limitations: unadjusted, age-adjusted and sex-adjusted and multivariable-adjusted zero-inflated Poisson regression results

\begin{tabular}{|c|c|c|c|c|}
\hline \multirow[b]{2}{*}{ Models } & \multicolumn{2}{|c|}{ Logistic section, OR $(95 \% \mathrm{Cl})^{\star}$} & \multicolumn{2}{|c|}{ Poisson section, RR $(95 \% \mathrm{Cl}) \dagger$} \\
\hline & Frailty & Prefrailty & Frailty & Prefrailty \\
\hline Model 1: unadjusted & $0.06(0.02$ to 0.24$)$ & $0.47(0.18$ to 1.21$)$ & $5.93(2.99$ to 11.75$)$ & $1.81(0.87$ to 3.74$)$ \\
\hline $\begin{array}{l}\text { Model 3: model } 2+\text { longest held } \\
\text { occupation }\end{array}$ & $0.11(0.02$ to 0.56$)$ & $0.46(0.16$ to 1.32$)$ & 3.94 (2.11 to 7.36$)$ & 1.30 (0.70 to 2.43$)$ \\
\hline $\begin{array}{l}\text { Model 6: model 5+self-perceived } \\
\text { vision ability }\end{array}$ & $0.11(0.02$ to 0.68$)$ & $0.34(0.05$ to 2.25$)$ & 4.13 (2.25 to 7.59$)$ & 1.22 (0.68 to 2.20$)$ \\
\hline $\begin{array}{l}\text { Model } 7 \text { : model } 6+\text { self-perceived } \\
\text { hearing ability }\end{array}$ & $0.11(0.02$ to 0.59$)$ & 0.33 (0.06 to 1.84$)$ & $4.16(2.27$ to 7.60$)$ & $1.21(0.67$ to 2.16$)$ \\
\hline
\end{tabular}

Statistically significant estimates (at the $5 \%$ level) are displayed in bold.

"Logistic section of the regression model estimates the log-odds of belonging to the 'sure-zero'/'not-at-risk' class.

†Poisson section of the regression model estimates the count of IADL limitations for those estimated to belong to the 'non-sure zero'/'at risk' latent class.

$\mathrm{OR}$, odds ratio; $\mathrm{RR}$, rate ratio. 
Table 5 Zero-inflated Poisson regression results for the association between frailty status and instrumental activities of daily living limitations (model 7)

\begin{tabular}{|c|c|c|}
\hline Covariate & $\begin{array}{l}\text { Logistic section } \\
\text { OR }(95 \% \mathrm{Cl})^{*}\end{array}$ & $\begin{array}{l}\text { Poisson section } \\
\text { RR }(95 \% \mathrm{Cl}) \dagger\end{array}$ \\
\hline \multicolumn{3}{|l|}{ Frailty } \\
\hline Robust & 1.00 & 1.00 \\
\hline Prefrailty & 0.32 (0.06 to 1.84$)$ & 1.21 (0.67 to 2.16$)$ \\
\hline Frailty & $0.11(0.02$ to 0.59$)$ & 4.16 (2.27 to 7.60$)$ \\
\hline \multicolumn{3}{|l|}{ Sex } \\
\hline Male & 1.00 & 1.00 \\
\hline Female & 6.17 (1.31 to 29.40$)$ & 1.02 (0.69 to 1.50$)$ \\
\hline \multicolumn{3}{|c|}{ Age group (years) } \\
\hline $60-64$ & 1.00 & 1.00 \\
\hline $65-69$ & $1.88(0.23$ to 15.80$)$ & 1.88 (0.71 to 4.96$)$ \\
\hline $70-74$ & 0.62 (0.08 to 4.85$)$ & 2.22 (0.78 to 6.32$)$ \\
\hline $75-79$ & 0.24 (0.02 to 2.66$)$ & 2.26 (0.91 to 5.60$)$ \\
\hline$\geq 80$ & $0.05(0.00$ to 0.79$)$ & 3.44 (1.31 to 9.02$)$ \\
\hline
\end{tabular}

\section{Longest-held}

occupation

\begin{tabular}{|c|c|c|}
\hline $\begin{array}{l}\text { Never-employed/skill } \\
\text { level } 1\end{array}$ & 1.00 & 1.00 \\
\hline Skill level 2 & 4.34 (0.89 to 21.33$)$ & 1.04 (0.69 to 1.57$)$ \\
\hline Skill level 3 or 4 & $6.42(1.34$ to 30.57$)$ & 1.37 (0.97 to 1.93$)$ \\
\hline \multicolumn{3}{|l|}{ Social support } \\
\hline Poor/Moderate & 1.00 & 1.00 \\
\hline Strong & 5.81 (0.45 to 74.44$)$ & 1.38 (1.08 to 1.78$)$ \\
\hline \multicolumn{3}{|l|}{ Multimorbidity } \\
\hline None or 1 & 1.00 & 1.00 \\
\hline$\geq 2$ & $1.49(0.45$ to 4.95$)$ & 1.37 (1.03 to 1.83$)$ \\
\hline \multicolumn{3}{|l|}{ Self-perceived vision } \\
\hline Poor/fair & 1.00 & 1.00 \\
\hline $\begin{array}{l}\text { Good/very good/ } \\
\text { excellent }\end{array}$ & $3.03(0.61$ to 15.49$)$ & 1.11 (0.76 to 1.63$)$ \\
\hline \multicolumn{3}{|l|}{ Self-perceived hearing } \\
\hline Poor/fair & 1.00 & 1.00 \\
\hline $\begin{array}{l}\text { Good/very good/ } \\
\text { excellent }\end{array}$ & $0.76(0.16$ to 3.71$)$ & 0.88 (0.71 to 1.10$)$ \\
\hline
\end{tabular}

The reference category is 1.00 . Statistically significant estimates (at the $5 \%$ level) are displayed in bold.

*Logistic section of the regression model estimates the log-odds of belonging to the 'sure-zero'/'not-at-risk' class.

†Poisson section of the regression model estimates the count of IADL limitations for those estimated to belong to the 'non-sure zero'/'at risk' latent class.

$\mathrm{OR}$, odds ratio; $\mathrm{RR}$, rate ratio.

indicates higher dependency level. Higher dependency results in higher need for support services and caregiver burden. Caring and supporting older adults is a family obligation in Sri Lanka. However, the sustainability of this traditional value system is challenged due to shift in family structures: extended to nuclear due to economic migration, both internal and external. In the absence of an established formal social support system for older adults, caregiving is becoming a challenging task. Methodologically comparable cross-country studies investigating the prevalence of disabilities across frailty status will enable researchers to understand context specific macrolevel and microlevel factors that are associated with disability.

\section{CONCLUSIONS}

The prevalence of $\geq 1$ IADL limitations was high among rural community-dwelling frail older adults in Sri Lanka. Findings imply the greater support and care required for rural Sri Lankan frail older adults to live independently in the community.

\section{Author affiliations}

${ }^{1}$ Research Department of Primary Care and Population Health, University College London, London, UK

${ }^{2}$ Department of Disability Studies, Faculty of Medicine, University of Kelaniya, Ragama, Sri Lanka

${ }^{3}$ Department of Community Medicine, Faculty of Medicine, University of Colombo, Colombo, Sri Lanka

${ }^{4}$ Research Department of Epidemiology and Public Health, University College London, London, UK

Acknowledgements Authors acknowledge all the participants of this study who generously gave their time and effort to respond the questionnaire. We also thank the support provided by the Director General of Health Services, Provincial Director of Health Services-Sabaragamuwa province, District Secretary and Regional Director of Health Services-Kegalle district, all the Divisional secretaries and the Grama Niladhari officers of the respective areas investigated in this study. We would like to thank Mrs Krishna Kurunathapillai for performing the Tamil translation of all the study instruments. We would also like to thank the research assistants (H P M Hewavitharane, P G I P Udayakumara, D M N Kumara, A P A Jayasinghe, M V J D Abeyrathna) and the field assistants (H K P Ariyadasa, K D S S Dissanayaka, W G C Pussallamada, G R K M Rathnasiri, W S T Weerasinghe, R J S Dharmawansha, W R P Wijenayake, V P D I Danarathna, R G R D Anuruddha) for their precious support with data collection. We would also like to acknowledge Professor $A R$ Wickremasinghe, Department of Public Health, Faculty of Medicine, University of Kelaniya, Sri Lanka for his invaluable guidance on data cleaning process. We thank Department of Community Medicine, Faculty of Medicine, University of Colombo for handling finances and arranging logistics for the field study.

Contributors DDS, KRW, MCW, GR conceived and designed the study. DDS and MCW collected the data. DDS and SS analysed the data. DDS drafted the manuscript. KRW, MCW, GR, SS critically revised the manuscript.

Funding DDS (corresponding author) is a Commonwealth scholar, funded by UK government (LKCS-2015-678).

Disclaimer The funder had no role in study design, data collection, data analysis, interpretation, drafting the paper or decision to publish.

Competing interests None declared.

Patient and public involvement Patients and/or the public were not involved in the design, or conduct, or reporting, or dissemination plans of this research.

Patient consent for publication Not required.

Ethics approval The ethical clearance for this study was obtained from two ethics review committees at University College London (Project ID: 8155/001) and Faculty of Medicine, University of Colombo, Sri Lanka (Protocol No. EC-16-071).

Provenance and peer review Not commissioned; externally peer reviewed.

Data availability statement All data relevant to the study are included in the article or uploaded as supplementary information.

Open access This is an open access article distributed in accordance with the Creative Commons Attribution Non Commercial (CC BY-NC 4.0) license, which 
permits others to distribute, remix, adapt, build upon this work non-commercially, and license their derivative works on different terms, provided the original work is properly cited, appropriate credit is given, any changes made indicated, and the use is non-commercial. See: http://creativecommons.org/licenses/by-nc/4.0/.

\section{ORCID iDs}

Dhammika Deepani Siriwardhana http://orcid.org/0000-0003-2313-3095

Kate R Walters http://orcid.org/0000-0003-2173-2430

\section{REFERENCES}

1 World Health Organization. How to use the ICF: a practical manual for using the International classification of functioning, disability and health (ICF), exposure draft for Comment. Geneva: WHO, 2013.

2 Fried LP, Tangen CM, Walston J, et al. Frailty in older adults: evidence for a phenotype. J Gerontol A Biol Sci Med Sci 2001;56:M146-57.

3 Clegg A, Young J, Iliffe S, et al. Frailty in elderly people. Lancet 2013;381:752-62.

4 Fried LP, Ferrucci L, Darer J, et al. Untangling the concepts of disability, frailty, and comorbidity: implications for improved targeting and care. J Gerontol A Biol Sci Med Sci 2004;59:M255-63.

5 British Geriatrics Society and the Royal College of General Practitioners. Fit for Frailty - Developing, commissioning and managing services for people living with frailty in community settings 2015.

6 Vermeiren S, Vella-Azzopardi R, Beckwée D, et al. Frailty and the prediction of negative health outcomes: a meta-analysis. J Am Med Dir Assoc 2016;17:1163.e1-17.

7 Gale CR, Cooper C, Sayer AA. Prevalence of frailty and disability: findings from the English longitudinal study of ageing. Age Ageing 2015;44:162-5

8 Amer MS, Mabrouk RA, Abdel Dayem TK, et al. Prevalence of functional impairment among frail elderly. Egypt J Hosp Med 2014;54:15-19.

9 Wong $\mathrm{CH}$, Weiss $\mathrm{D}$, Sourial $\mathrm{N}$, et al. Frailty and its association with disability and comorbidity in a community-dwelling sample of seniors in Montreal: a cross-sectional study. Aging Clin Exp Res 2010;22:54-62.

10 Rajapakse S, Maithripala C, Ibrahim S, et al. Disease patterns and care of older people in Sri Lanka. Indian J Gerontol 2012;26:351-66.

11 Manini T. Development of physical disability in older adults. Curr Aging Sci 2011;4:184-91.

12 Siriwardhana DD, Weerasinghe MC, Rait G, et al. Prevalence of frailty in rural community-dwelling older adults in Kegalle district of Sri Lanka: a population-based cross-sectional study. BMJ Open 2019;9:e026314.

13 Radloff LS. The CES-D scale: a self-report depression scale for research in the general population. Appl Psychol Meas 1977;1:385-401.

14 de Silva VA, Ekanayake S, Hanwella R. Validity of the Sinhala version of the centre for epidemiological studies depression scale (CES-D) in out-patients. Ceylon Med J 2014;59:8-12.

15 Craig CL, Marshall AL, Sjöström M, et al. International physical activity questionnaire: 12 -country reliability and validity. Med Sci Sports Exerc 2003;35:1381-95.

16 Arambepola C. Abdominal obesity and its association with selected risk factors of coronary heart disease in an adult population in the district of Colombo, 2004.
17 Siriwardhana DD, Walters K, Rait G, et al. Cross-Cultural adaptation and psychometric evaluation of the Sinhala version of Lawton instrumental activities of daily living scale. PLoS One 2018;13:e0199820.

18 Lekamwasam S, Karunatilake K, Kankanamge SKP, et al. Physical dependency of elderly and physically disabled; measurement concordance between 10-item Barthel index and 5-item shorter version. Ceylon Med J 2011;56:114-8.

19 Lawton MP, Brody EM. Assessment of older people: selfmaintaining and instrumental activities of daily living. Gerontologist 1969;9:179-86.

$20 \mathrm{Ng}$ T-P, Niti M, Chiam P-C, et al. Physical and cognitive domains of the instrumental activities of daily living: validation in a multiethnic population of Asian older adults. J Gerontol A Biol Sci Med Sci 2006;61:726-35.

21 Mahoney FI, Barthel DW. Functional evaluation: the Barthel index: a simple index of independence useful in scoring improvement in the rehabilitation of the chronically ill. Md State Med J 1965;14:61-5.

22 Department of Census and Statistics. Sri Lanka standard classification of occupation (SLSCO-08); 2008.

23 Weich S, Lewis G, Poverty LG. Poverty, unemployment, and common mental disorders: population based cohort study. BMJ 1998;317:115-9.

24 van den Akker M, Buntinx F, Knottnerus JA. Comorbidity or multimorbidity. Eur J Gen Pract 1996;2:65-70.

25 Karunaratne S, Hanwella R, de Silva V. Validation of the Sinhala version of the Montreal cognitive assessment in screening for dementia. Ceylon Med J 2011;56:147-53.

26 Dalgard OS, Dowrick C, Lehtinen V, et al. Negative life events, social support and gender difference in depression: a multinational community survey with data from the Odin study. Soc Psychiatry Psychiatr Epidemiol 2006;41:444-51.

27 StataCorp. Stata 14 Stata survey data reference manual. College Station, TX: Stata Press, 2014.

28 Pittman B, Buta E, Krishnan-Sarin S, et al. Models for analyzing zeroinflated and overdispersed count data: an application to cigarette and marijuana use. Nicotine Tob Res 2018. doi:10.1093/ntr/nty072. [Epub ahead of print: 18 Apr 2018].

29 Vandenbroucke JP, von Elm E, Altman DG, et al. Strengthening the reporting of observational studies in epidemiology (STROBE): explanation and elaboration. PLoS Med 2007; 4:e297.

30 Godin J, Armstrong JJ, Rockwood K, et al. Dynamics of frailty and cognition after age 50: why it matters that cognitive decline is mostly seen in old age. J Alzheimers Dis 2017;58:231-42.

31 Jekel K, Damian M, Wattmo C, et al. Mild cognitive impairment and deficits in instrumental activities of daily living: a systematic review. Alzheimers Res Ther 2015;7:17.

32 Robertson DA, Savva GM, Kenny RA. Frailty and cognitive impairment--a review of the evidence and causal mechanisms. Ageing Res Rev 2013;12:840-51.

33 MoCA: Montreal-Cognitive Assessment. Frequently asked questions 2019. Available: https://www.mocatest.org/faq/ [Accessed 2 Apr 2019].

34 Slaets JPJ. Vulnerability in the elderly: frailty. Med Clin North Am 2006;90:593-601.

35 Vaingankar JA, Chong SA, Abdin E, et al. Prevalence of frailty and its association with sociodemographic and clinical characteristics, and resource utilization in a population of Singaporean older adults. Geriatr Gerontol Int 2017;17:1444-54. 